\title{
Cetuximab-Coated Thermo-Sensitive Liposomes Loaded with Magnetic Nanoparticles and Doxorubicin for Targeted EGFR-Expressing Breast Cancer Combined Therapy
}

This article was published in the following Dove Press journal:

International Journal of Nanomedicine

Buyankhishig Dorjsuren ${ }^{1, *}$ Birendra Chaurasiya $\mathbb{1}^{2, *}$

Zixuan $\mathrm{Ye}^{\prime}$

Yanyan Liu'

Wei $\mathrm{Li}^{3}$

Chaoyang Wang

Di Shi ${ }^{4}$

Colin E Evans (D) ${ }^{2}$

Thomas J Webster (iD ${ }^{4}$

Yan Shen'

'Department of Pharmaceutics, China Pharmaceutical University, Nanjing 210009, People's Republic of China; ${ }^{2}$ Department of Pediatrics, Critical Care Division, Stanley Manne Children's Research Institute, Ann \& Robert H. Lurie Children's Hospital of Chicago, Northwestern University Feinberg School of Medicine, Chicago, IL, USA; ${ }^{3}$ Department of Cardiology, Affiliated Hospital of Yangzhou University, Yangzhou 225002, People's Republic of China; ${ }^{4}$ Department of Chemical Engineering, Northeastern University, Boston, MA, USA

*These authors contributed equally to this work
Background: One major limitation of cancer chemotherapy is a failure to specifically target a tumor, potentially leading to side effects such as systemic cytotoxicity. In this case, we have generated a cancer cell-targeting nanoparticle-liposome drug delivery system that can be activated by near-infrared laser light to enable local photo-thermal therapy and the release of chemotherapeutic agents, which could achieve combined therapeutic efficiency.

Methods: To exploit the magnetic potential of iron oxide, we prepared and characterized citric acid-coated iron oxide magnetic nanoparticles (CMNPs) and encapsulated them into thermo-sensitive liposomes (TSLs). The chemotherapeutic drug, doxorubicin (DOX), was then loaded into the CMNP-TSLs, which were coated with an antibody against the epidermal growth factor receptor (EGFR), cetuximab (CET), to target EGFR-expressing breast cancer cells in vitro and in vivo studies in mouse model.

Results: The resulting CET-DOX-CMNP-TSLs were stable with an average diameter of approximately $120 \mathrm{~nm}$. First, the uptake of TSLs into breast cancer cells increased by the addition of the CET coating. Next, the viability of breast cancer cells treated with CET-CMNP-TSLs and CET-DOX-CMNP-TSLs was reduced by the addition of photo-thermal therapy using nearinfrared (NIR) laser irradiation. What is more, the viability of breast cancer cells treated with CMNP-TSLs plus NIR was reduced by the addition of DOX to the CMNP-TSLs. Finally, photothermal therapy studies on tumor-bearing mice subjected to NIR laser irradiation showed that treatment with CMNP-TSLs or CET-CMNP-TSLs led to an increase in tumor surface temperature to $44.7^{\circ} \mathrm{C}$ and $48.7^{\circ} \mathrm{C}$, respectively, compared with saline-treated mice body temperature ie, $35.2^{\circ} \mathrm{C}$. Further, the hemolysis study shows that these nanocarriers are safe for systemic delivery. Conclusion: Our studies revealed that a combined therapy of photo-thermal therapy and targeted chemotherapy in thermo-sensitive nano-carriers represents a promising therapeutic strategy against breast cancer.

Keywords: breast cancer, cetuximab, doxorubicin, iron oxide magnetic nanoparticles, epidermal growth factor receptors, combined therapy

\section{Introduction}

Despite the incidence of breast cancer increasing globally in women and that it is still considered to be one of the most deadliest cancer types, ${ }^{1}$ treatment approaches have remained relatively the same over the past decades relying on conventional chemotherapy and radiotherapy. The overexpression of the epidermal growth factor receptor (EGFR) contributes to tumor progression, including increased cancer cell
Correspondence: Yan Shen; Thomas Webster

Tel +86 (025) 8327I305

Email shenyan@cpu.edu.cn;

th.webster@northeastern.edu
International Journal of Nanomedicine 2020:15 820I-8215

8201

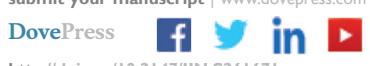

http://doi.org/10.2147/1!N.s.

(c) (i) (5) 2020 Dorisuren et al. This work is published and licensed by Dove Medical Press Limited. The full terms of this license are available at https://www.dovepress.com/

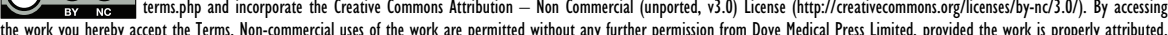
For permission for commercial use of this work, please see paragraphs 4.2 and 5 of our Terms (https://www.dovepress.com/terms.php). 
proliferation and inhibited apoptosis. ${ }^{2}$ Cetuximab (CET) is a monoclonal antibody treatment that has been used to target EGFR signaling in cancer cells ${ }^{3}$ and has demonstrated anti-cancer effects in EGFR-overexpressing tumor cells in vitro and in vivo. ${ }^{4-6}$ Furthermore, CET is already approved for clinical use in head and neck cancer and colorectal cancer. ${ }^{7,8}$ Doxorubicin (DOX) is another example of a clinically approved anti-cancer drug that activates cell apoptosis, ${ }^{9}$ but the use of chemotherapeutic agents such as CET and DOX is often hampered by their side effects, including dose-dependent cardio-toxicity. ${ }^{10,11}$

Similarly, many chemotherapeutic agents are limited by their lack of specificity towards cancer cells, which can result in systemic cytotoxicity. ${ }^{12}$ In the last two decades, various novel cancer therapeutic strategies have been proposed to improve the local targeting of anti-cancer treatments to the tumor cells; these include therapies that are responsive to external stimuli such as light, magnetic field, ultrasound, and radio-frequency. ${ }^{3}$ For example, magnetic nanoparticles (MNPs) have been used for targeted drug delivery in combination with external exposure to a magnetic field that enables the local delivery of therapeutic and diagnostic agents. ${ }^{13,14}$ Iron oxide $\left(\mathrm{Fe}_{3} \mathrm{O}_{4}\right)$ MNPs have also been used as a delivery system for chemotherapeutics, gene therapeutics, and photothermal therapeutics ${ }^{15,16}$ owing to their favorable biocompatibility, ability to serve as a nutrient, and ease of size control. ${ }^{17}$ Besides these advantages, iron oxide MNPs generate heat when exposed to near-infrared (NIR) laser irradiation. ${ }^{18}$ Related to nanoparticle-based drug delivery systems, thermo-sensitive liposomes (TSLs) have also been employed for the delivery of various drugs, as a result of their biocompatibility, biodegradability, and loading capacity. ${ }^{19,20}$ A recent study, for example, indicated that iron oxide nanoparticles exhibit excellent photo-thermal treatment efficacy when excited by NIR laser irradiation. Loading of these iron oxide nanoparticles into TSLs improved NIR-laser-triggered drug release.

These findings, as well as the rationale described above, led us to question whether DOX and iron oxide MNPs could be loaded into CET-coated TSLs to produce a combination of photothermal therapy with targeted drug delivery to improve anti-cancer efficacy in breast cancer.

\section{Materials and Methods}

\section{Materials}

Fe (II) chloride tetrahydrate (99\%) and Fe (III) chloride hexahydrate $(97 \%)$ were purchased from Shanghai
Lingfeng Chemical Reagent Co., Ltd, Shanghai, China. Citric acid, ethanol, and chloroform were purchased from Sinopharm Chemical Reagent Co., Ltd, Shanghai, China. 1.2-Dipalmitoyl-sn-glycero-3-phosphocholine (DPPC), 1.2-Distearoyl-sn-glycero-3-phosphoehanolamine-N-[methoxy(polyethyleneglycol)-2000](DSPEmPEG2000), and DSPE-mPEG-COOH were purchased from Shanghai Advanced Vehicle Technology Co., Ltd, Shanghai, China. 1-myristoyl-2-palmitoyl-sn-glycero -3-phosphocholine (MPPC) was purchased from Sigma Reagent Co., Ltd, Shanghai, China. DOX was obtained from Beijing HuaFeng United Technology Co., Ltd, Beijing, China. EDC $\cdot \mathrm{HCl}$ was provided by Shanghai Medpep Co., Ltd, Shanghai, China. N-Hydroysuccinimide (NHS) was purchased from Aladdin Biochemical Technology Co., Ltd, Shanghai, China. Hyclone ${ }^{\circledR}$-Trypsin, Hyclone ${ }^{\mathbb{R}}$-Penicillin, Streptomycin and Hyclone ${ }^{\mathbb{R}}$-DMEM were obtained from GE Healthcare Life Sciences, UK and Fetal Bovine Serum (FBS) was obtained from CLARK Bioscience, USA. 3-[4,5-dimethylthialzol-2-yl]-2,5- diphenyltetrazolium bromide (MTT) and the bicinchoninic acid protein assay (BCA) were purchased from Jiangsu Keygen Biotech Co., Ltd, Nanjing, China. Erbitux ${ }^{\circledR}$ (Cetuximab, CET) was purchased from Merck \& Co., Inc, Shanghai, China. A sepharose CL-4B desalting column was purchased from Shanghai Yuanye Biotechnology Co., Ltd, Shanghai, China. The SKBR-3 and MCF-7 breast cancer cell lines were used, which were all were brought from the American Type Culture Collection (ATCC).

\section{Methods}

\section{Synthesis of Citric Acid-Coated $\mathrm{Fe}_{3} \mathrm{O}_{4}$-MNPs (CMNPs)}

The CMNPs were prepared by chemical precipitation based on a previously described method with little modification. ${ }^{21}$ Briefly, MNPs were first prepared by dissolving $0.875 \mathrm{~g} \mathrm{FeCl}_{2}$ and $2.375 \mathrm{~g} \mathrm{FeCl}_{3}\left(\mathrm{Fe}^{2+}: \mathrm{Fe}^{3+}=1: 2\right)$ in $40 \mathrm{~mL}$ of double-distilled water (DDI water) in a threeneck flask with stirring at $100 \mathrm{rpm}$ in the presence of $\mathrm{N}_{2}$ gas for $15 \mathrm{~min}$ at $80^{\circ} \mathrm{C}$. Then, the stirring speed was increased to $1000 \mathrm{rpm}$ and $5 \mathrm{~mL} \mathrm{NH} \mathrm{NH}_{4} \mathrm{OH}(28 \% \mathrm{~W} / \mathrm{V})$ was added to the flask and stirred for an additional 30 min. To coat MNPs with citric acid, the temperature of the solution was increased to $95^{\circ} \mathrm{C}$ and citric acid $(1 \mathrm{mg} / \mathrm{mL})$ was added drop by drop. The reaction was allowed to proceed further for $90 \mathrm{~min}$. After cooling to room temperature, the solution was diluted to twice its original volume with DDI water and subjected to magnetic 
separation for $10 \mathrm{~min}$. The supernatant containing CMNPs was continuously washed with $0.5 \mathrm{~L}$ of DDI water in a 10 $\mathrm{kDa}$ molecular weight cut-off (MWCO) hollow fiber module (Spectrum Laboratories) to remove excess citric acid and $\mathrm{NH}_{4} \mathrm{OH}$ and to obtain the CMNPs.

\section{Preparation of CMNP-TSLs}

CMNP-TSLs were prepared by using a solvent evaporation method followed by extrusion. Lipid mixtures of 30mg DPPC, $6 \mathrm{mg}$ DSPE-mPEG-2000 and 4mg MPPC were added to a round-bottom flask. This mixture was dissolved in a chloroform/methanol solution $(2: 1 \mathrm{~V} / \mathrm{V})$. The organic solvent was removed using a rotary evaporator (RE-52AA, Shanghai, China) at $100 \mathrm{psi}$ and $39^{\circ} \mathrm{C}$ with a water bath for $2 \mathrm{~h}$. The resulting dry thin film was rehydrated with an ammonium sulfate $(250 \mathrm{mM}, \mathrm{pH} 4.0)$ solution containing CMNPs $(1 \mathrm{mg} / \mathrm{mL})$ for $20 \mathrm{~min}$ at $45^{\circ}$ C. The hydrated solution was then sonicated for $15 \mathrm{~min}$. After sonication, the liposomes were extruded for 20 cycles using double-stacked polycarbonate membranes with $0.05,0.1$ and $0.2 \mu \mathrm{m}$ pore sizes (Whatman, NJ, USA). The un-encapsulated CMNPs were removed by centrifugation (KDC-140HR, Anhui, China) at 4000g for 10 min to obtain the CMNP-TSLs.

\section{Preparation of DOX-Loaded CMNP-TSLs (DOX-CMNP-TSLs)}

DOX was loaded into the CMNP-TSLs using an ammonium sulfate gradient based on a method described previously. ${ }^{11}$ An ammonium sulfate (250 mM, pH 4.0) plus CMNP-TSLs suspension was dialyzed against deionized water at $4^{\circ} \mathrm{C}$ for $24 \mathrm{~h}$. DOX was added into the CMNP-TSLs suspension at a weight ratio of 1:20 (DOX: Lipids) and incubated (HH-6, Jiangsu, China) at $50^{\circ} \mathrm{C}$ for $30 \mathrm{~min}$. Finally, the unencapsulated DOX was removed by dialysis and the DOX-CMNP-TSLs were stored at $4^{\circ} \mathrm{C}$ until further use.

\section{Preparation of CET-Coated DOX-CMNP-TSLs (CET-DOX-CMNP-TSLs)}

CET-DOX-CMNP-TSLs were prepared as described ${ }^{22}$ with the following modifications. First, $0.6 \mathrm{mg}$ DSPEmPEG-COOH was added to NHS and EDC (molar ratio $1: 1$ ) in a pH 7.4 PBS solution for 30 mins. Next, $2.0 \mathrm{mg}$ of CET was added at $4^{\circ} \mathrm{C}$ and incubated for $12 \mathrm{~h}$ to obtain CET-DSPE-mPEG-COOH. Then, the DOX-CMNP-TSLs solution and CET-DSPE-mPEG-COOH solution were mixed and shaken at $4^{\circ} \mathrm{C}$ in the dark for $5 \mathrm{~h}$ to obtain CETDOX-CMNP-TSLs. The unconjugated CET was removed by chromatography using a Sepharose CL-4B column

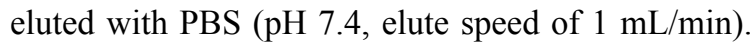

\section{Determination of Loading Efficiency of DOX into CMNP-TSLs}

The quantity of CMNPs and DOX in the TSLs was determined by spectrophotometry. For the content of CMNPs, the measurement was carried out by using aqua regia to dissolve the sample and by using DDI water to dilute the sample. Then, the sample solution was added to $0.2 \mathrm{~mL}$ of a $0.5 \mathrm{~mol} / \mathrm{L}$ sulfosalicylic acid solution. Next, $1.0 \mathrm{~mL}$ of an $\mathrm{NH}_{3}-\mathrm{NH}_{4} \mathrm{Cl}$ buffer solution was added, and the total volume was increased to $5 \mathrm{~mL}$ with the addition of DDI water followed by gentle shaking and measurement of absorbance of the solution at 380-460 nm using a UVVIS spectrophotometer (UV1800, Shimadzu, Japan) to obtain the maximum absorption wavelength. For the content of DOX, the measurement was conducted after denaturing the emulsion with absolute alcohol, and the absorbance value at $480 \mathrm{~nm}$ was obtained using a UVVIS spectrophotometer to calculate DOX. The CMNPs and DOX concentrations were determined using a standard curve. The following equation was used to calculate encapsulation efficiency (Equation 1):

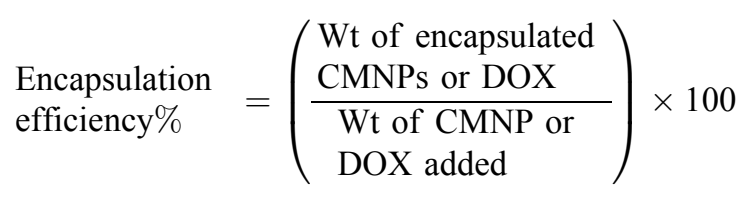

(Equation 1)

\section{Determination of Conjugation Efficiency of CET Onto TSLs}

Conjugation efficiency was evaluated using the BCA protein assay according to the manufacturer's instructions (Jiangsu Keygen Biotech Co., Ltd). Briefly, the working reagent was prepared by mixing 50 parts of the $\mathrm{BCA}$ Reagent A with 1 part of the BCA Reagent B (50:1, Reagent A:B). After the incubation of $20 \mu \mathrm{L}$ sample/standard solution and $200 \mu \mathrm{L}$ working agent at $37^{\circ} \mathrm{C}$ for 30 min, their absorbances were determined at the wavelength of $570 \mathrm{~nm}$. Unconjugated CET was removed by chromatography using a Sepharose CL-4B column eluted with PBS ( $\mathrm{pH}$ 7.4). The peak retention times of TSLs and free CET were measured at $\lambda_{\max } 500 \mathrm{~nm}$ and $280 \mathrm{~nm}$ by a UV spectrophotometer, respectively. Then, a standard curve of absorbance versus the concentration of protein was obtained, and the amount of unreacted CET in the supernatant was determined from the curve. The conjugation 
efficiency of CET to TSLs was calculated according to the following formulation (Equation 2):

$$
\text { Conjugation efficiency }=\left(1-\frac{\mathrm{Cfree} * \mathrm{~V} 1}{m_{0}}\right) \times 100 \%
$$

(Equation 2)

Where, $\mathrm{m}_{0}$ represents the amount of the CET added, $\mathrm{V}_{1}$ represents the total elution volume collected for free CET and $\mathrm{C}_{\text {free }}$ represents the concentration obtained by the BCA kit for the free CET eluted sample.

\section{Characterization of CMNPs, TSLs and CET-DOX- CMNP-TSLs}

The particle size and zeta potential of CMNPs, TSLs, and CET-DOX-CMNP-TSLs were determined by dynamic light scattering (DLS) using a Nano-ZS90 (Malvern Instruments Ltd., UK). DLS analysis was performed at a scattering angle of $90^{\circ}$ at $25^{\circ} \mathrm{C}$ in the auto-measuring mode. Surface morphology of the nanoparticles was observed by transmission electron microscope (TEM) (JEOL JEM 1010, Japan) analysis. A vibrating sample magnetometer (PPMS-9, USA) was used to determine the magnetic properties of the CMNPs.

\section{Assessment of Magnetic Resonance Response of CMNP-TSLs}

CMNP-TSLs were formulated into concentrations of 0-0.8 mM (concentration based on Fe ions) in an aqueous solution. A pharma scan broker (Skyra $3.0 \mathrm{~T}$, Germany) magnetic resonance imager was used to measure T2 values. The parameters for magnetic resonance response were set as follows: field of view (FOV) at $200 \mathrm{~mm}$, repetition time (TR) at $2000 \mathrm{~min}$, and the echo time (TE) at $40 \mathrm{~min}$.

\section{Measurement of Photo-Thermal Sensitivity of CMNPs in CET-DOX-CMNP-TSLs}

Aqueous suspensions of CET-DOX-CMNP-TSLs were prepared and $1 \mathrm{~mL} / \mathrm{sample}$ was loaded into a 96-well microplate. Next, the sample was irradiated by NIR at $\lambda_{\max } 808 \mathrm{~nm}$ with a laser at $2 \mathrm{~W} / \mathrm{cm}^{2}$ for $5 \mathrm{~min}$ and imaged with a thermal imaging camera (PCE-TC 3, FLIR Corporation, USA) every $1 \mathrm{~min}$. In addition, in order to study the relationship between the concentration of CMNPs and the effect of photo-thermal heating, CMNPTSLs were formulated into a series of aqueous solutions at different concentrations of 20,50,100,200, and 500 $\mu \mathrm{g} /$ $\mathrm{mL}$ of CMNP-TSLs. The temperature of the sample solution was measured every 1 minute using a thermocouple and TSLs were used as a blank control.

\section{Determination of in vitro NIR-Triggered DOX Release}

In vitro release of DOX from the various formulations (free-DOX, DOX-TSLs, DOX-CMNP-TSLs, and CETDOX-CMNP-TSLs) was studied for $24 \mathrm{~h}$ at three different $\mathrm{pH}$ levels, ie, 7.4, 6.8, and 5.5 to determine the influence of $\mathrm{pH}$ and NIR irradiation. Samples from all the formulations were suspended into $10 \mathrm{~mL}$ of releasing buffer at $\mathrm{pH}$ 7.4, 6.8, and 5.5 separately, at a concentration of $10 \mathrm{mg} /$ $\mathrm{mL}$, and placed into dialysis bags (MWCO 10kDa). A set of Nessler tubes (Fisher Scientific) was filled with $20 \mathrm{~mL}$ of the same releasing media and the dialysis bags containing samples were carefully dipped into the tubes and placed in a water bath at $37^{\circ} \mathrm{C}$. To determine the effect of $\mathrm{pH}$ and NIR on drug release, DOX-CMNP-TSLs and CET-DOX-CMNP-TSLs were treated with NIR ( $\lambda \max 808$ $\mathrm{nm}, 2 \mathrm{~W} / \mathrm{cm}^{-2} \mathrm{t}=5 \mathrm{~min}$ ) and the differences in the release of DOX from the same samples without NIR treatment were studied for $24 \mathrm{~h}$ at predetermined time point intervals, ie, $0.5,1,2,4,6,8,10,12$ and $24 \mathrm{~h}$. The collected samples were analyzed for the quantification of DOX using a UV-Vis spectrophotometer (Agilent 8453, USA).

\section{Assessment of Cellular Uptake of TSLs, CET-TSLs into Breast Cancer Cells}

The cellular uptake efficiency of TSLs and CET-TSLs into two different cell lines, ie, SKBR-3 (over expressed EGFR) and MCF-7 (low expressed EGFR) breast cancer cells (Chinese Academy of Sciences, Shanghai, China) was studied by flow cytometry (Miltenyi MACSQuant Analyzer 10, Germany) and fluorescence microscopy (Olympus IX53, Japan).

The fluorescent TSLs and CET-TSLs were synthesized by the following steps: Weigh DPPC, DSPE-PEG2000 and MPPC according to liposome prescription, weigh $12 \mu \mathrm{g}$ of coumarin 6 and dissolve in chloroform followed by evaporating for 3 hours to remove the organic solvent, and form a thin film on the bottom of the bottle. Fluorescent TSLs were obtained after using $45^{\circ} \mathrm{C}$ deionized water to hydrate the film. Fluorescent CET-TSLs were prepared by incubating DSPE-PEG-CET and Fluorescent TSLs overnight at a mass ratio of 1:1 and purified by CL-4B agarose gel column. The fluorescent TSLs and CET-TSLs should be diluted and the final preparations contain the same amount of fluorescein $(50 \mathrm{ng} / \mathrm{mL})$. 
Both cell lines (SKBR-3 and MCF-7) were seeded in 6 -well plates $\left(6 \times 10^{5}\right.$ cells/well $)$ and cultured for $24 \mathrm{~h}$. Then, the culture medium was discarded and cells were cleaned 3 times with PBS. Next, the cells were incubated with $2 \mathrm{~mL}$ of serum-free medium containing fluorescent TSLs and CET-TSLs for $0.5,1$ and $2 \mathrm{~h}$ in two separate plates. Cell culture medium was discarded and the cells were cleaned three times with cold PBS. Then, the cells were imaged using a fluorescence microscope followed by the collection of cells for the quantification of uptake efficiency by a flow cytometer.

\section{Determination of in vitro Cytotoxicity of CET-CMNP-TSLs and CET-DOX-CMNP-TSLs}

The cells were cultured in RPMI 1640 medium with $10 \%$ fetal bovine serum (FBS) and 1\% penicillin/streptomycin. The cytotoxicity of CET-CMNP-TSLs and CET-DOXCMNP-TSLs on two breast cancer cell lines (SKBR-3 and MCF-7) was determined by MTT assays in two steps (as in A and B shown).

\section{Cytotoxicity of CMNP in CMNP-TSLs and CET-CMNP-TSLs}

To determine the cytotoxicity of CMNP in CMNP-TSLs and CET-CMNP-TSLs, SKBR-3 (passage 3) and MCF-7 cells (passage 3 ) in the logarithmic growth phase were digested with trypsin, resuspended in culture medium, and seeded in 96-well plates at a density of $5 \times 10^{3}$ cells/well. The cells were cultured for $24 \mathrm{~h}$ at $37^{\circ} \mathrm{C}$. Next, the culture medium was gently replaced with 100 $\mu \mathrm{L}$ of diluted concentrations of CMNP-TSLs and CETCMNP-TSLs $(0,10,20,50,100,200,500$, and $1000 \mu \mathrm{g} /$ $\mathrm{mL}$, of CMNPs in FBS-free cell culture medium RPMI 1640) per well. In addition, NIR and free DOX groups were used as controls, the concentration of free DOX was the same as the loaded amount in the DOX-CMNP-TSLs and CET-DOX-CMNP-TSLs. The plates were again placed into incubator at same temperature and duration. Next, the plates were kept at $37^{\circ} \mathrm{C}$ for $24 \mathrm{~h}$ irradiated with NIR at $\lambda_{\max } 808 \mathrm{~nm}$ at a laser intensity of $2 \mathrm{~W} / \mathrm{cm}^{2}$ for 5 min continuously twice. Cell culture medium was aspirated and the cells were three times washed with PBS to remove the residual from CMNP-TSLs and CET-CMNPTSLs. Next, a pre-prepared $100 \mu \mathrm{L}$ MTT solution (1 mg/ $\mathrm{mL}$ ) was added into each well and the plates were placed into an incubator at $37^{\circ} \mathrm{C}$. After $4 \mathrm{~h}$ of incubation, the plates were collected and the MTT solution was replaced with $150 \mu \mathrm{L}$ of DMSO and gently shaken for $10 \mathrm{~min}$ before measurements at an absorbance of $\lambda=570 \mathrm{~nm}$ were taken using a microplate reader (ELX800, USA).

\section{Combined Cytotoxicity of DOX and CMNP in DOX-CMNP-TSLs and CET-DOX-CMNP-TSLs}

Both cell lines (SKBR-3 and MCF-7) were cultured and prepared in the same way as mentioned in the above section for MTT assays. To determine the combinational cytotoxicity level of DOX and CMNP in DOX-CMNPTSLs and CET-DOX-CMNP-TSLs, both samples were diluted to concentrations $(0,10,20,50,100,200,500$, and $1000 \mu \mathrm{g} / \mathrm{mL}$ ) with a ratio of DOX: CMNP $=1: 15$ in each diluted concentration. Next, the cells were incubated with the above samples for $24 \mathrm{~h}$. Further, DOX-CMNPTSLs and CET-DOX-CMNP-TSLs groups were then irradiated with a laser at $\lambda_{\max } 808 \mathrm{~nm}$ with $3 \mathrm{~W} / \mathrm{cm}^{2}$ for 10 min. For the assessment of cancer cell viability, MTT assays were performed as described above and the synergistic effect in terms of the combination index (CI) of chemotherapy and photo-thermal therapy of CMNPs in SKBR-3 and MCF-7 cells was calculated using CompuSyn software (ComboSyn Inc, Paramus, NJ; www.combosyn.com) with the following Equation3:

$$
\begin{aligned}
& \text { Combination index }(\mathrm{CI})=\frac{(D)_{1,50}}{\left(D_{50}\right)_{1}}+\frac{(D)_{2,50}}{\left(D_{50}\right)_{2}} \\
& \text { (Equation 3) }
\end{aligned}
$$

Where, $\mathrm{CI}$ is the combination index, $\left(\mathrm{D}_{\mathrm{X}}\right)_{1}$ and $\left(\mathrm{D}_{\mathrm{X}}\right)_{2}$ are the concentrations of DOX and CMNP in TSLs without NIR resulting in 50\% growth inhibition; and (D) $)_{1}$ and (D) are the concentrations of DOX and CMNP in TSLs with NIR resulting in equal growth inhibition.

\section{Assessment of in vivo Photo-Thermal Treatment Efficacy}

The ethical and legal approval from the Animal Welfare and Research Ethics Committee of China Pharmaceutical University (No.20190413-003) was obtained prior to the commencement of animal experiments. All the animal experiments were conducted in full compliance with the ethical guidelines of China Pharmaceutical University. The photo-thermal efficiency study was conducted in tumorbearing BALB/C mice (Qinglongshan Farms, Nanjing, China). Approximately $1 \times 10^{5}$ SKBR-3 cells were injected subcutaneously into the armpit region of BALB/c nude mice (seven weeks old, 20-25 g). Two weeks after the cell injection and when the tumors grew to $180-200 \mathrm{~mm}^{3}$ in diameter, all mice $(\mathrm{n}=15)$ were divided into 3 groups $(\mathrm{n}=5)$ and injected with $200 \mu \mathrm{L}$ of normal saline, CMNP- 
TSLs and CET-CMNP-TSLs (equal to CMNP $500 \mu \mathrm{g} / \mathrm{mL}$ ) through the tail vein, respectively. After $24 \mathrm{~h}$, the tumors of the mice were irradiated with a NIR laser $(808 \mathrm{~nm}, 2$ $\mathrm{W} / \mathrm{cm}^{2}$ ) for $5 \mathrm{~min}$ and during irradiation, an infrared camera was used to image the tumor and record tumor temperatures every $1 \mathrm{~min}$.

\section{Assessment of Biosafety of CMNP in Formulations - Hemolysis Assay}

To determine the biosafety effect of all formulations (ie, CMNPs, CMNP-TSLs, CET-CMNP-TSLs and CETCMNP-TSLs+NIR), a hemolysis assay was conducted. For this, blood samples from healthy rabbits were collected into heparinized tube and red blood cells (RBCs) were separated by centrifugation at $1000 \mathrm{rpm}$ for 10 min. The collected RBCs were washed three times with normal saline. For positive and negative controls, $2 \%$ RBCs suspensions were made with deionized water and normal saline separately. Next, all samples were diluted with normal saline at a concentration of CMNP at $10,20,30,40$ and $50 \mu \mathrm{g} / \mathrm{mL}$ and were incubated with $2 \%$ of $\mathrm{RBCs}(2.5 \mathrm{~mL})$ at $37^{\circ} \mathrm{C}$ for $3 \mathrm{~h}$. Further, to determine the effect of NIR, CET-CMNP-TSLs group was irradiated with NIR radiation at $2 \mathrm{~W} / \mathrm{cm}^{2}$ for $5 \mathrm{~min}$. After that, all treated samples were centrifuged at $1000 \mathrm{rpm}$ for $10 \mathrm{~min}$ to compare the clarity of the samples. To determine the rate of hemolysis, the supernatant from all samples was collected and the absorbance was measured at $570 \mathrm{~nm}$ using a microplate reader (BioTek, USA). The hemolysis rate is calculated by following Equation 3.

$$
\text { Hemolysis rate }(\%)=\frac{(A m-A 0)}{(A 1-A 0)} 100 \quad \text { (Equation }
$$

Where, $A_{m}$ is the value at each detected concentration level, $A_{1}$ is the value measured with positive control and $A_{0}$ is the value measured with the negative control.

\section{Statistical Analysis}

All quantitative data are expressed as the mean \pm standard deviation (SD). Pairwise comparisons were analyzed using Student's t-tests. $p$ values $<0.05$ were considered statistically significant.

\section{Results}

\section{Synthesis and Characterization of CMNPs, TSLs, CMNP-TSLs and CET-DOX-CMNP-TSLS}

A schematic representation of the CET-DOX-CMNP-TSLs is provided in Figure 1. The distribution of hydrodynamic diameters for the CMNPs, TSLs, CMNP-TSLs and CETDOX-CMNP-TSLs was measured by DLS (Figure 2A). The average diameters recorded for CMNPs, TSLs, CMNPTSLs, and CET-DOX-CMNP-TSLs were $8.11 \pm 1.12 \mathrm{~nm}$, $98.54 \pm 2.71 \mathrm{~nm}, 101.25 \pm 3.38 \mathrm{~nm}$ and $117.45 \pm 3.52 \mathrm{~nm}$ respectively; and the zeta potentials measured were -26.65 , $-32.05,-29.33$, and $-18.21 \mathrm{mV}$, respectively. Next, the shape and morphology of the nanoparticles were determined by TEM. CMNPs, TSLs, CMNP-TSLs, and CET-DOXCMNP-TSLs were found to be spherical shaped. The encapsulation efficiency (EE) calculated for CMNPs and DOX in TSLs was $37 \pm 2.1 \%$ and $87.9 \pm 1.4 \%$. BCA results showed that the unreacted CET was $14.84 \mu \mathrm{g} / \mathrm{mL}$ while the initial concentration of the CET was $30.17 \mu \mathrm{g} / \mathrm{mL}$ in $1 \mathrm{mg} / \mathrm{mL}$ TSLs. Therefore, the conjugation efficiency of CET to TSLs was determined to be $50.8 \%$.
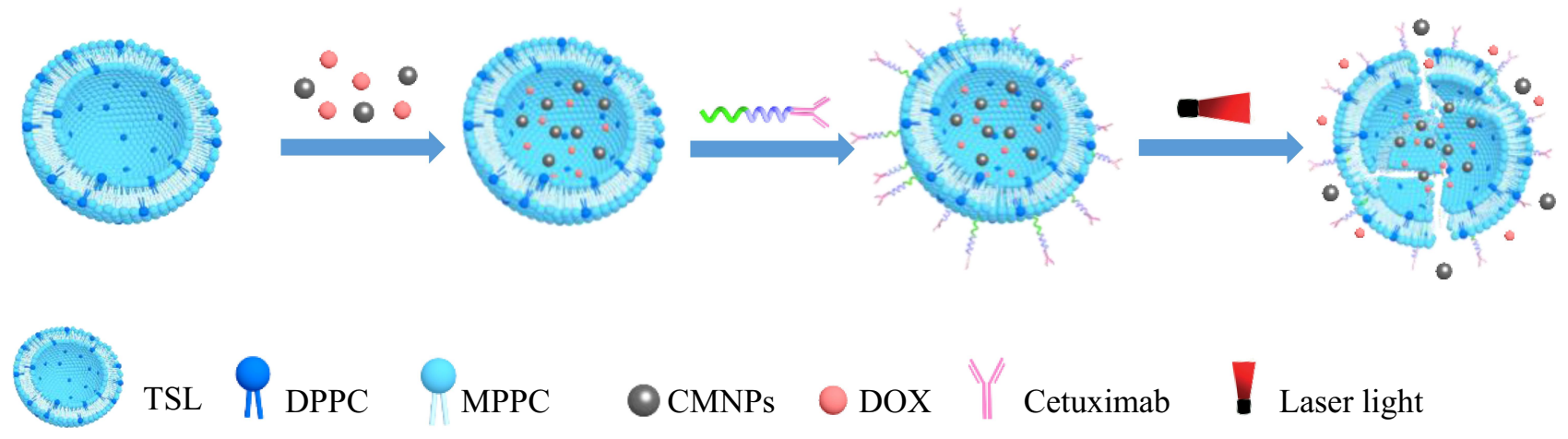

TSL R DPPC
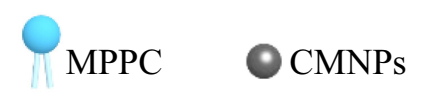

DOX
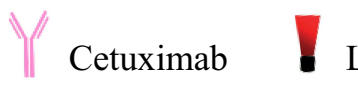

Laser light

Figure I Schematic illustration of NIR-triggered DOX release from CET-DOX-CMNP-TSLs. 
A
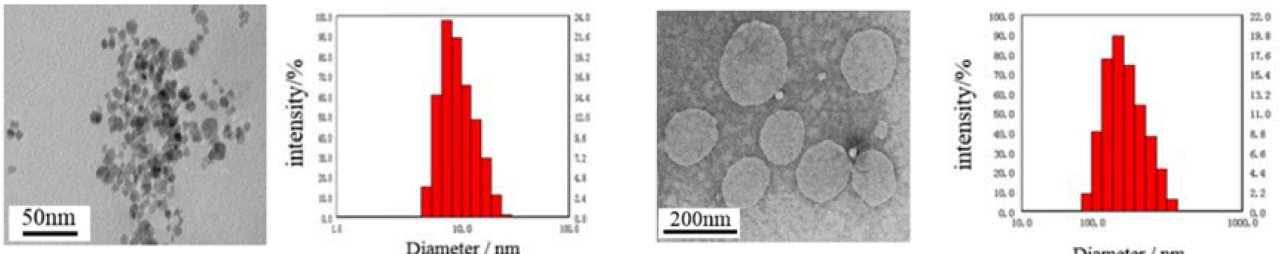

Diameter / nm
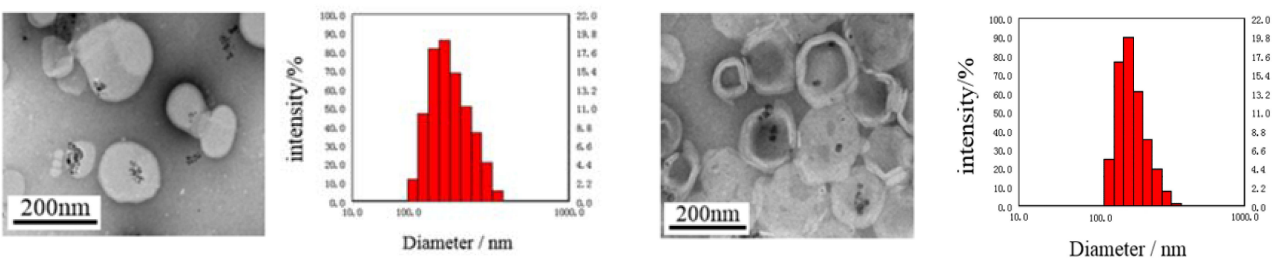

\begin{tabular}{cccc}
\hline Formulation & Diameter $(\mathrm{nm})$ & Zeta potential(mV) & PDI \\
\hline CMNPs & $8.11 \pm 1.12$ & $-26.65 \pm 2.27$ & 0.331 \\
TSLs & $98.54 \pm 2.71$ & $-32.05 \pm 1.83$ & 0.211 \\
CMNP-TSLs & $101.25 \pm 3.38$ & $-29.33 \pm 0.54$ & 0.269 \\
CET-DOX-CMNP-TSLs & $117.45 \pm 3.52$ & $-18.21 \pm 1.43$ & 0.138 \\
\hline
\end{tabular}

B

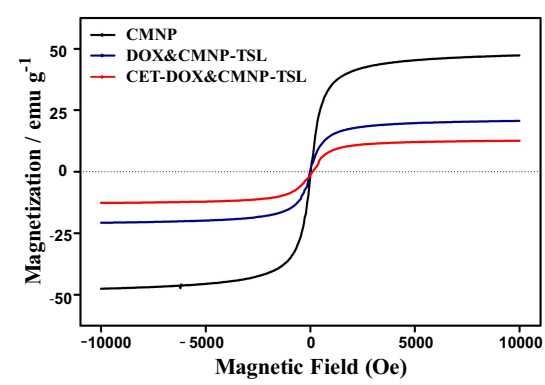

E

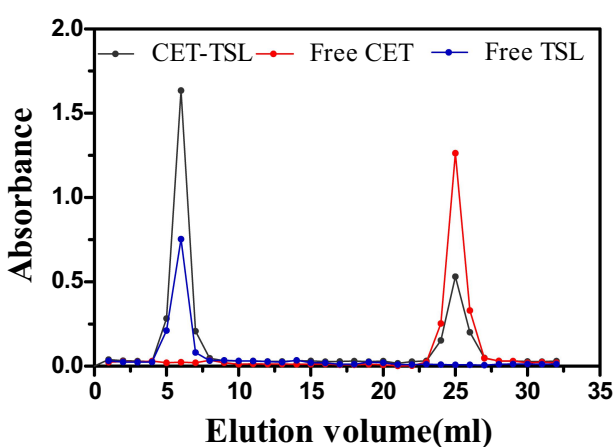

C

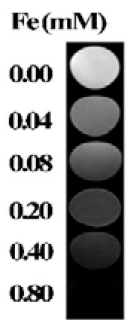

D

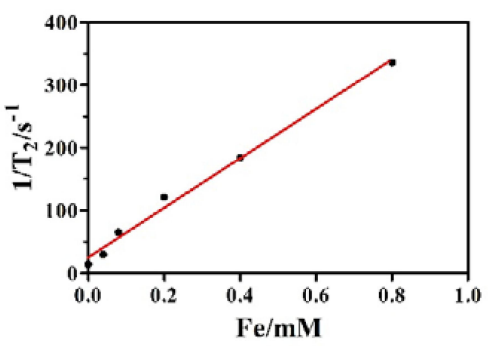

F

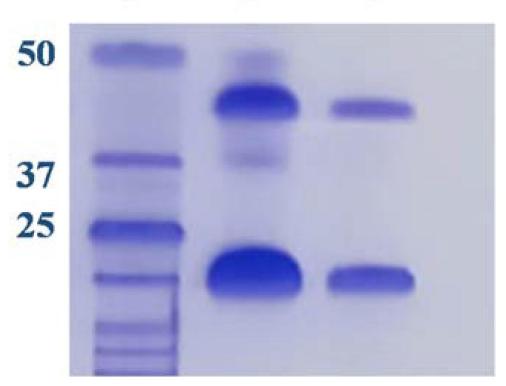

Figure 2 Characterization of CMNPs, TSLs, CMNPs-TSLs, and CET-DOX-CMNP-TSLs. (A) TEM images and size distributions as measured by DLS; (B) Normalized fielddependent magnetization curve for the CMNPs and CMNP-TSLs; (C) $T_{2}$-Weighted MR images of CMNP -TSLs aqueous solutions with various Fe concentrations; (D) Plot of $\mathrm{I} / \mathrm{T}_{2}$ over Fe ion concentration $(\mathrm{mM})$ of the CMNP-TSLs aqueous solution, the slope indicates the specific relaxivity $\left(r_{2}\right)$; (E) Chromatogram for CET-TSLs, Free CET and Free TSLs; and (F) SDS-Page electrophoresis profile of the (I) Protein ladder, (2) CET and (3) CET-TSLs.

The magnetization curve of CMNPs as measured by VSM was drawn in the range of $-10,000$ Oe $\sim 10,000$ Oe (Figure 2B). The saturation magnetization of the CMNPs, CMNP-TSLs, and CET-DOX-CMNP-TSLs was 46.24
22.59 and $12.58 \mathrm{emu} / \mathrm{g}$, respectively. The magnetic nature of the CMNPs was confirmed by their movement towards a magnet placed adjacent to the CMNPs solution. As shown in Figure $2 \mathrm{C}$, the signal intensity of the $T_{2}$ - 
weighted MR images decreased with an increase in the iron concentration, indicating a concentration-dependent $T_{2}$ signal. A linear relationship was observed when $1 / T_{2}$ was plotted against the Fe ion concentration (Figure 2D). The CMNPs had a magnetization saturation value (Ms) of $25.2 \mathrm{emu} / \mathrm{g}^{-1}$ and a transverse relaxation rate $\left(\mathrm{r}_{2}\right)$ of 25.2 $\mathrm{mM}^{-1} \mathrm{~s}^{-1}$, indicating that the CMNP-TSLs carriers have magnetic response characteristics in vitro that are consistent with contrast agents that can be used for $T_{2}$ MRI contrast imaging.

\section{Photo-Thermal Sensitivity Effect of CMNP-TSLs}

For the photo-thermal effect of NIR laser irradiation on CMNP-TSLs, NIR laser irradiation was established at a $\lambda_{\max }$ of $808 \mathrm{~nm}$ with a heat flow rate of $2 \mathrm{~W} / \mathrm{cm}^{2}$ through the CMNP-TSLs solution for $8 \mathrm{~min}$. The photothermal graphic images of the CMNP-TSLs solution and the aqueous solution are shown in Figure 3A1 (brighter images indicate higher temperatures). The thermal image of the CMNP-TSLs solution became brighter (ie, warmer) with an increase in NIR laser irradiation time and CMNP concentration. As confirmed by the quantification curves in Figure 3A2, the photo-thermal effect of NIR laser irradiation on CMNP-TSLs was a function of CMNP concentration. When the concentration of CMNPs was 500 $\mu \mathrm{g} / \mathrm{mL}$, the temperature of the solution rose to $69.6^{\circ} \mathrm{C}$ within $5 \mathrm{~min}$ for NIR irradiation, while the equivalent temperature of the aqueous CMNP-free TSL solution was only $31.1^{\circ} \mathrm{C}$. The average rise in temperature across all of the CMNP concentrations was 2.23 times greater than that of the CMNP-free TSL control group. These results showed that the CMNP-TSLs rapidly converted NIR laser light energy into thermal energy.

\section{In vitro NIR-Triggered Release of DOX}

Release of DOX from free-DOX, DOX-TSLs, CETDOX-CMNP-TSLs and DOX-CMNP-TSLs was compared with and without exposure to NIR irradiation at three $\mathrm{pH}$ levels (Figure 3B1-B3). The release pattern of DOX from free-DOX in all three $\mathrm{pH}$ levels (ie, 7.4, 6.8 and 5.4) was similar. Similarly, no significant changes were seen in the release of DOX from DOX-TSLs, CET-DOX-CMNP-TSLs and DOX-CMNP-TSLs at all
A1
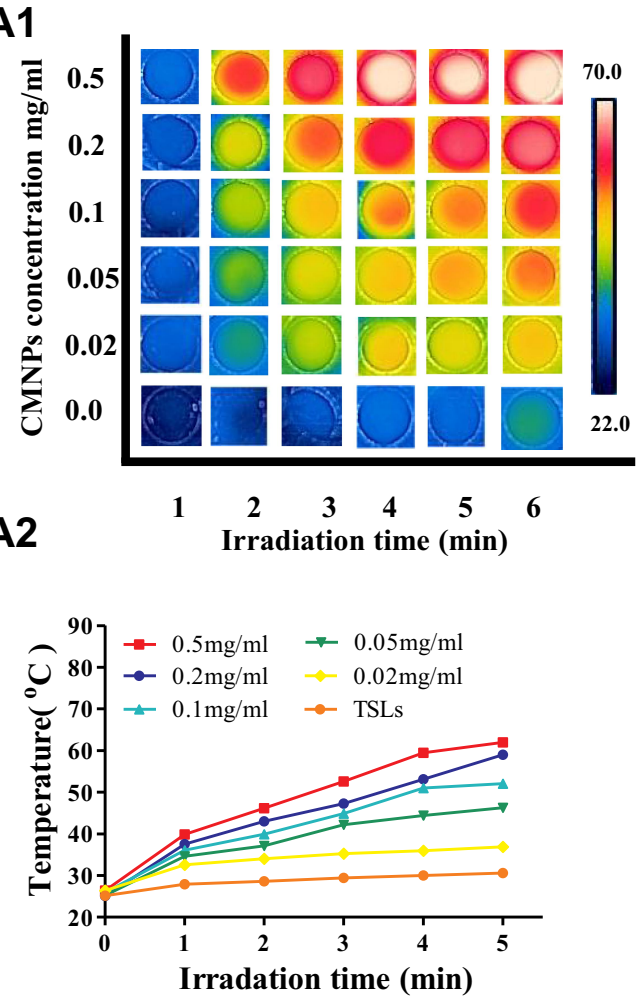

B1

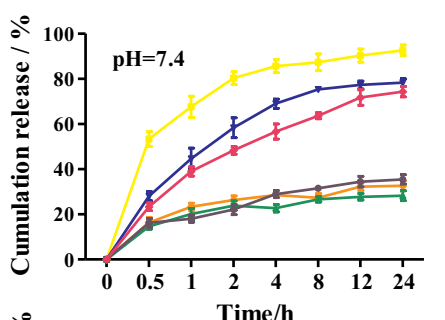

B2

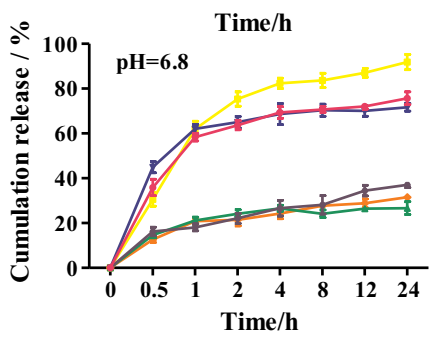

B3

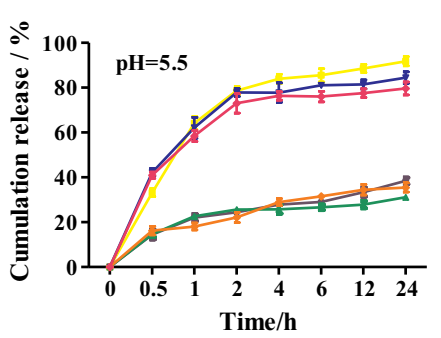

$=$ Free DOX

$\rightarrow$ DOX-TSL

$\rightarrow$ CET-DOX\&CMNP-TSL

$\rightarrow$ DOX\&CMNP-TSL

$\rightarrow$ DOX\&CMNP-TSL+NIR

$\rightarrow$ CET-DOX\&CMNP-TSL+NIR $\perp$

- Free DOX

$\simeq$ DOX-TSL

$\rightarrow$ CET-DOX\&CMNP-TSL

$\rightarrow$ DOX\&CMNP-TSL

$\rightarrow$ DOX\&CMNP-TSL+NIR

$\rightarrow$ CET-DOX\&CMNP-TSL+NIR

Figure 3 Effect of NIR laser irradiation on DOX release from DOX-TSLs and DOX-CMNPs-TSLs: (AI) Infrared thermal images showing the photo-thermal effect of NIR laser irradiation on water and CMNP-TSLs at different irradiation times $\left(\lambda_{\max } 808 \mathrm{~nm}, 2 \mathrm{~W} / \mathrm{cm}^{-2}\right)$ and CMNP concentration; (A2) Photo-thermal heating curves of TSLs solution and CMNP-TSLs at various CMNP concentrations and various irradiation times $\left(\lambda_{\max } 808 \mathrm{~nm}, 2 \mathrm{~W} / \mathrm{cm}^{-2}\right)$; and DOX release from different formulations at three different $\mathrm{pH}$ levels $(\mathbf{B I}) \mathrm{pH} 7.4,($ B2 $) \mathrm{pH} 6.8$, and $(\mathbf{B} 3) \mathrm{pH} 5.5$ with and without NIR irradiation $\left(\lambda_{\max } 808 \mathrm{~nm}, 2 \mathrm{~W} / \mathrm{cm}^{-2}, \mathrm{t}=5 \mathrm{~min}\right)(* \mathrm{p}<0.05, * * p<0.0 \mathrm{I})$. 
three $\mathrm{pH}$ levels, but significant differences were seen in the release pattern of DOX from DOX-CMNP-TSLs and CET-DOX-CMNP-TSLs after irradiation with NIR. At $\mathrm{pH} 7.4$, after $1 \mathrm{~h}$ of irradiation, DOX release from DOX-CMNP-TSLs was around twofold (ie, 42\%) from both formulations compared with only $22 \%$ from the non-irradiated counter formulations. After $24 \mathrm{~h}$, the release of DOX from DOX-CMNP-TSLs and CETDOX-CMNP-TSLs did not increase that much, only $37 \%$, but a significant increase (ie, $70 \%$ ) was found from the irradiated DOX-CMNP-TSLs and CET-DOXCMNP-TSLs. At pH 6.8 and pH 5.5, around a threefold increase (ie, $62 \%$ ) was recorded after $1 \mathrm{~h}$ of irradiation. After $24 \mathrm{~h}$, a DOX release of $84 \%$ from DOX-CMNPTSLs and CET-DOX-CMNP-TSLs with an irradiation at pH 5.5 was observed, but a similar amount of release (ie, 70\%) was observed at $\mathrm{pH}$ 6.8. These results showed that the release of DOX from DOX-CMNP-TSLs and CET-DOX-CMNP-TSLs increased with the exposure to NIR irradiation as well as at an acidic $\mathrm{pH}$.

\section{Breast Cancer Cell Uptake of TSLs and CET-TSLs and Cell Viability Following Treatment with CET-CMNP-TSLs, CET-DOX-CMNP-TSLs}

The cellular uptake of TSLs and CET-TSLs in SKBR-3 and MCF-7 cells was observed by fluorescence microscopy and quantitatively measured by flow cytometry (Figure 4A and B). After $2 \mathrm{~h}$ of treatment, the uptake of CET-coated TSLs increased into SKBR-3 comparing with the uncoated TSLs but not the MCF-7 cells. CET binding can therefore increase the uptake of TSLs into SKBR-3 breast cancer cells which have an over-expressed number of EGFR.

Results shown in Figure 4C and D represent the cell viability $\%$ of SKBR-3 and MCF-7, respectively, due to the presence of CMNPs in CMNP-TSLs and CET-CMNPTSLs. The cell viability of cells treated by NIR showed that only NIR would not cause obvious damage to cells. From the results, it can be seen that the cell viability decreased with an increase in sample concentration in both cancer cell lines, ie, SKBR-3 and MCF-7. At the highest concentration of $1000 \mu \mathrm{g} / \mathrm{mL}$, more than $80 \%$ of the cells survived in both cell lines treated with CETCMNP-TSLs. However, the cell viability \% significantly decreased to $60 \%$ and $75 \%$ for the SKBR-3 and MCF-7 cell lines with NIR treatment.
Similarly, the results shown in Figure $4 \mathrm{E}$ and F represent the cell viability \% of SKBR-3 and MCF-7 cells due to the presence of DOX and CMNP in the formulations showing the combinational chemotherapy and photo-thermal effect. At a higher CMNP concentration of $1000 \mu \mathrm{g} / \mathrm{mL}$, DOX-CMNP-TSLs and CET-DOXCMNP-TSLs showed cell viabilities of $50 \%$ and $35 \%$, respectively, which is higher than free DOX, but with the NIR irradiation, the cell viability markedly declined to $15 \%$ and $5 \%$ in the SKBR-3 cell line, lower than free DOX. That indicated the endocytosis of nanoparticles, especially the CET modified nanoparticles, combined with NIR-triggered drug release have stronger killing effect on cancer cells than free DOX. Similarly, at 1000 $\mu \mathrm{g} / \mathrm{mL}$, for the MCF-7 cells, cell viability was relatively higher (ie, 60\%) for the DOX-CMNP-TSLs and CETDOX-CMNP-TSLs than for the SKBR-3 cells, while the cell viability significantly declined to $25 \%$ and $20 \%$ with the treatment of NIR irradiation, respectively. However, the cell viability of DOX-CMNP-TSLs and CET-DOXCMNP-TSLs with NIR treatment was higher than free DOX in MCF-7 cells, which may be due to the less endocytosis of nanoparticles by MCF-7 cells.

Using a combination of a lower CMNP concentration of $50 \mu \mathrm{g} / \mathrm{mL}$ plus NIR laser treatment, the cell survival rate of the CET-DOX-CMNP-TSLs group was reduced compared with the DOX-CMNP-TSLs group, likely as a result of the CET-mediated increase in DOX uptake in both cells. The combination index of CET-DOX-CMNPTSLs calculated for SKBR-3 and MCF-7 cells was 0.491 and 0.516, respectively, which indicated a synergistic effect of DOX-mediated chemotherapy and CMNPmediated photo-thermal therapy.

\section{Photo-Thermal Impact of NIR Laser Irradiation Plus CET-CMNP-TSLs Treatment in Tumor-Bearing Mice}

As can be seen in Figure 5A and B, the tumor surface temperature in the normal saline group after 5 min of NIR laser irradiation was $35.2^{\circ} \mathrm{C}$. By contrast, the tumor temperature in the mice for CMNP-TSLs or CET-DOXCMNP-TSLs was $44.7^{\circ} \mathrm{C}$ and $48.7^{\circ} \mathrm{C}$, respectively, which was a significant difference between the two groups. This was because the CET modification can enhance the CMNP accumulation in the tumor site by EGFR-mediated active targeting, which results in higher temperature increases. These data showed that NIR laser irradiation- 
A

SK-BR-3
TSL

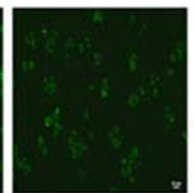

$1 \mathrm{~h}$
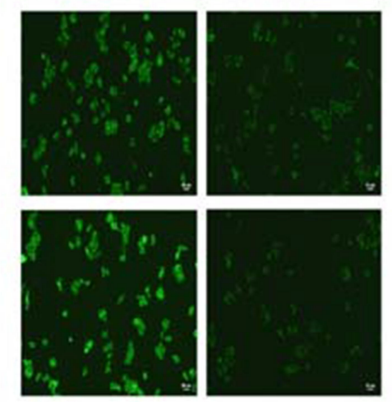

C

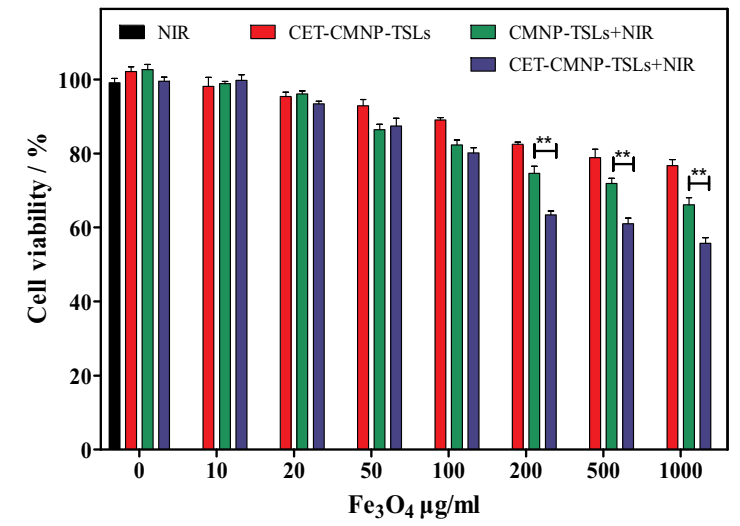

E

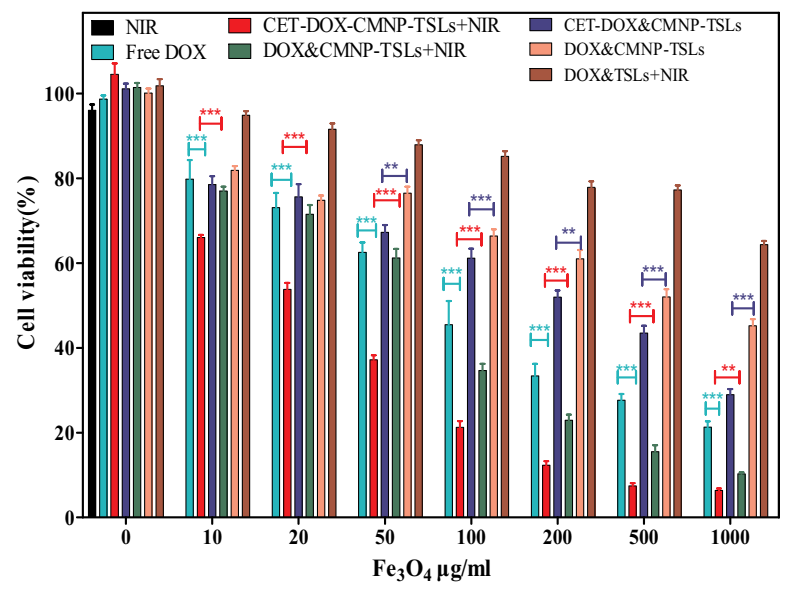

MCF-7

B

CET-TSL TSL

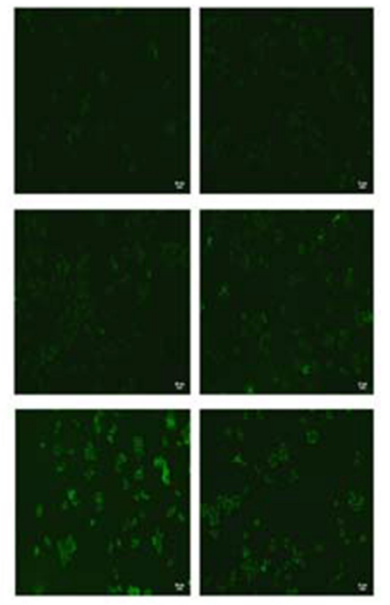

D

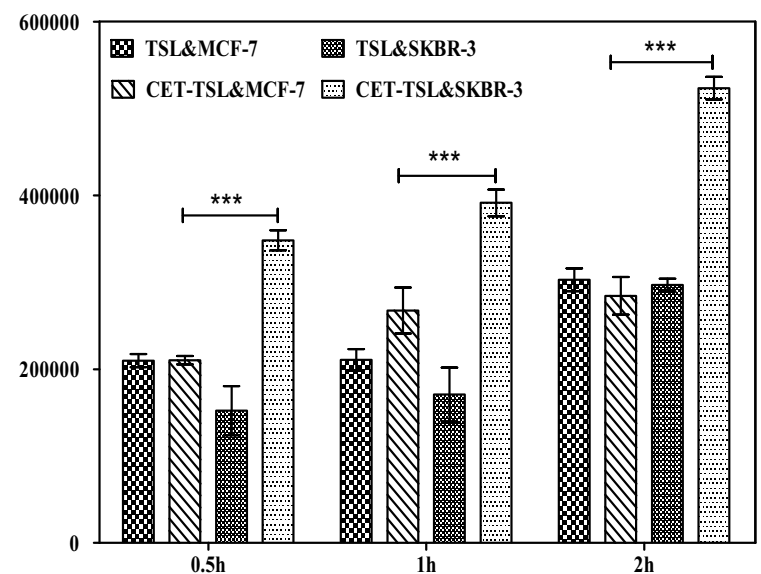

Time/h

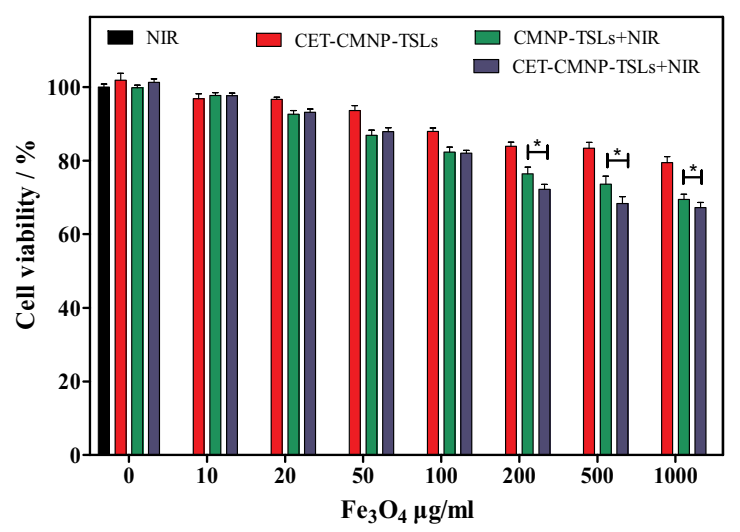

F

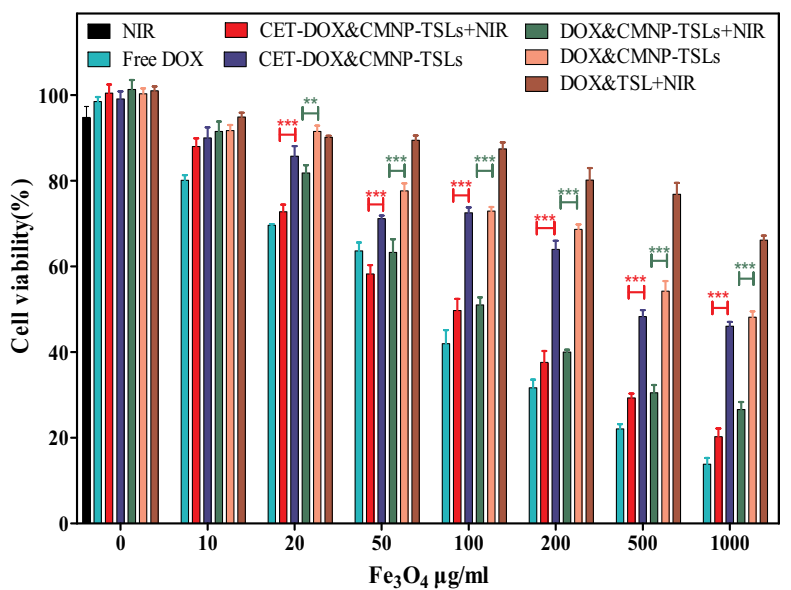

Figure 4 Cancer cell viability and uptake following treatment with CET-DOX-CMNP-TSLs. (A and B) Qualitative cellular uptake of TSLs coated with and without CET by SKBR-3 and MCF-7 cells imaged by fluorescence microscopy (scale bar $=50 \mu \mathrm{m}$ ) and the quantitative analysis of the same analyzed by flow cytometry $(\mathrm{n}=3$, $* * * 0<0.00 \mathrm{I}$ ); (C and D) Relative cell viability of SKBR-3 and MCF-7 cells incubated for $24 \mathrm{~h}$ with different concentrations of CMNP (as a function of Fe $\mathrm{O}_{4}$ ) in CET-CMNP-TSLs with or without NIR $\lambda_{\max } 808 \mathrm{~nm}$ laser irradiation $\left(2 \mathrm{~W} / \mathrm{cm}^{2}\right.$ for $\left.5 \mathrm{~min}\right)(\mathrm{n}=5)\left({ }^{*} p<0.05\right.$, $\left.{ }^{* *} p<0.01\right)$; (E and F) Cell viability of SKBR-3 and MCF-7 cells incubated for $24 \mathrm{~h}$ with CETDOX-CMNP-TSLs (as a combination function of DOX and CMNP at a ratio of I:I5) at the same concentration with and without NIR irradiation at $\lambda_{\text {max }} 808$ nm and 2 W/ $\mathrm{cm}^{2}$ for $5 \mathrm{~min}(\mathrm{n}=5)(* p<0.05, * * p<0.01$, $* * * p<0.001)$. 


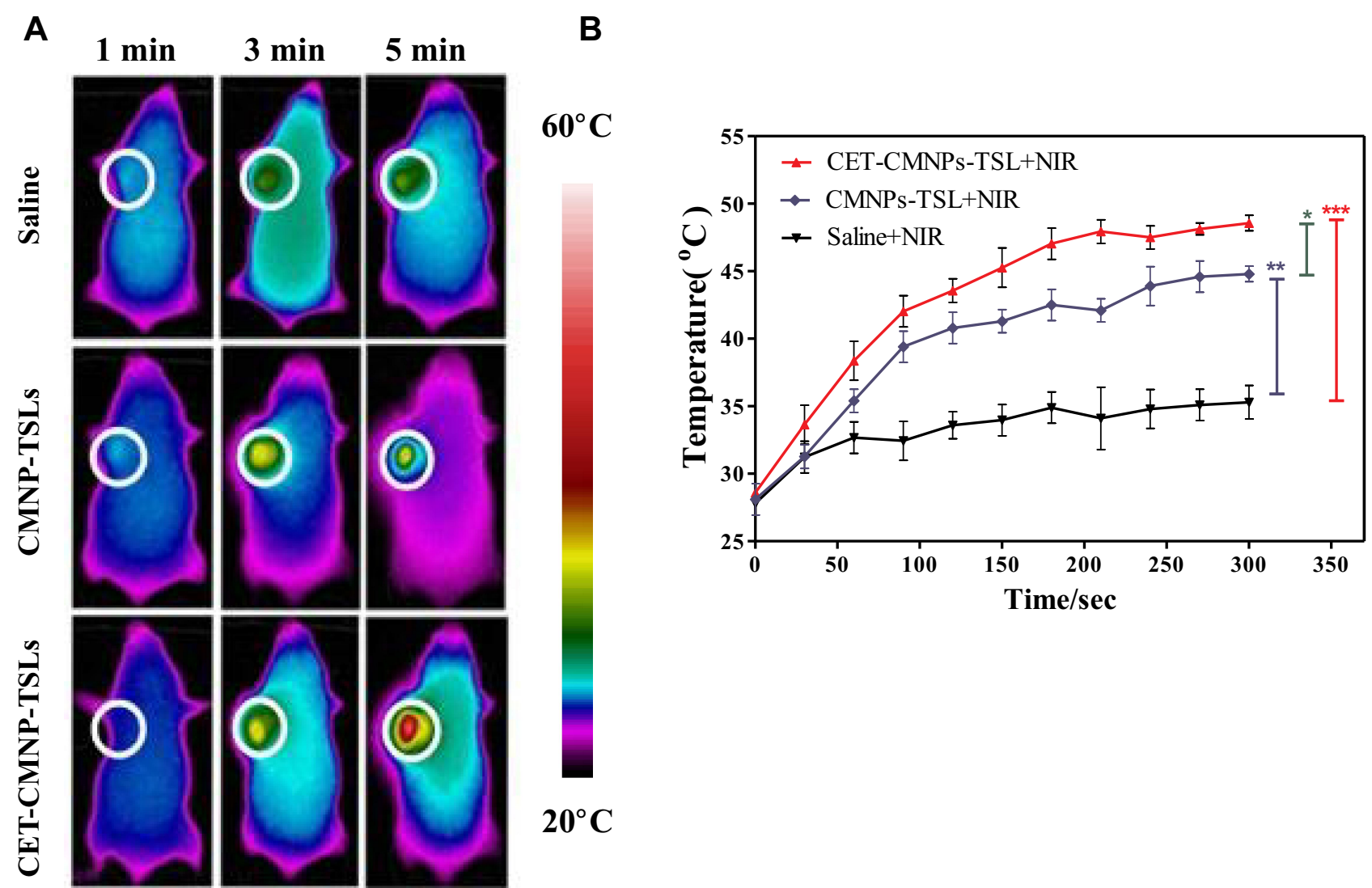

Figure 5 Photo-thermal effect of CMNP-TSLs treatment plus NIR laser irradiation on tumor temperature; (A) Thermographic images and (B) quantification of tumor temperatures in tumor-bearing mice following NIR laser irradiation for different time periods plus treatment with normal saline, CMNP-TSLs and CET-CMNP-TSLs. $\left({ }^{*} p<0.05, *_{p}<<0.01, *^{* * *} p<0.00 \mathrm{I}\right)$. The white circle represents the tumor site.

induced increases in tumor temperature were greater in mice receiving CMNP-TSLs or CET-DOX-CMNP-TSLs compared with saline and confirmed the photo-thermal properties of the CMNP-TSLs.

\section{Biosafety Study-Hemolysis Assay}

Hemolytic assays are important to conduct for formulations intended for systemic use, especially for those nanoformulations that require blood contact blood. A hemolysis assay was conducted to demonstrate the hemocompatibility of CMNP in the formulations with and without NIR irradiation (Figure 6). As shown in the photographs (Figure 6A), a 2\% v/v suspension of rabbit RBCs was exposed with different concentrations (10, 20, 30, 40, and $50 \mu \mathrm{g} / \mathrm{mL}$ ) of CMNPs in the formulations and no obvious hemolysis phenomenon was observed; all appeared similar to the -Ve control (exposed to normal saline). In contrast, the rabbit RBCs exposed to deionized water (+Ve control) had a significant hemolysis effect. The quantitative hemolysis \% of CMNP in the different formulations was quantified based on the absorbance of the supernatants (Figure 6B). Uncoated CMNPs showed a comparatively higher hemolysis and that may be due to Fe ions; similarly, NIR irradiated samples also showed a higher degree of hemolysis due to NIR irradiation. Overall, the results showed less than $4 \%$ hemolysis, suggesting excellent hemocompatibility of CMNP even with NIR irradiation.

\section{Discussion}

In this study, we designed CET-DOX-CMNP-TSLs as a novel drug delivery system, which when integrated with NIR laser irradiation therapy, enhanced antitumor efficacy.

Despite tremendous advancements in drug delivery techniques, effective treatments for many forms of cancer are still lacking. ${ }^{23}$ In the development of novel and effective delivery vehicles for anti-cancer therapies, studies have suggested that a smaller nanoparticle size $(<200 \mathrm{~nm})$ enhances accumulation of the nanoparticles at tumor sites through the enhanced 


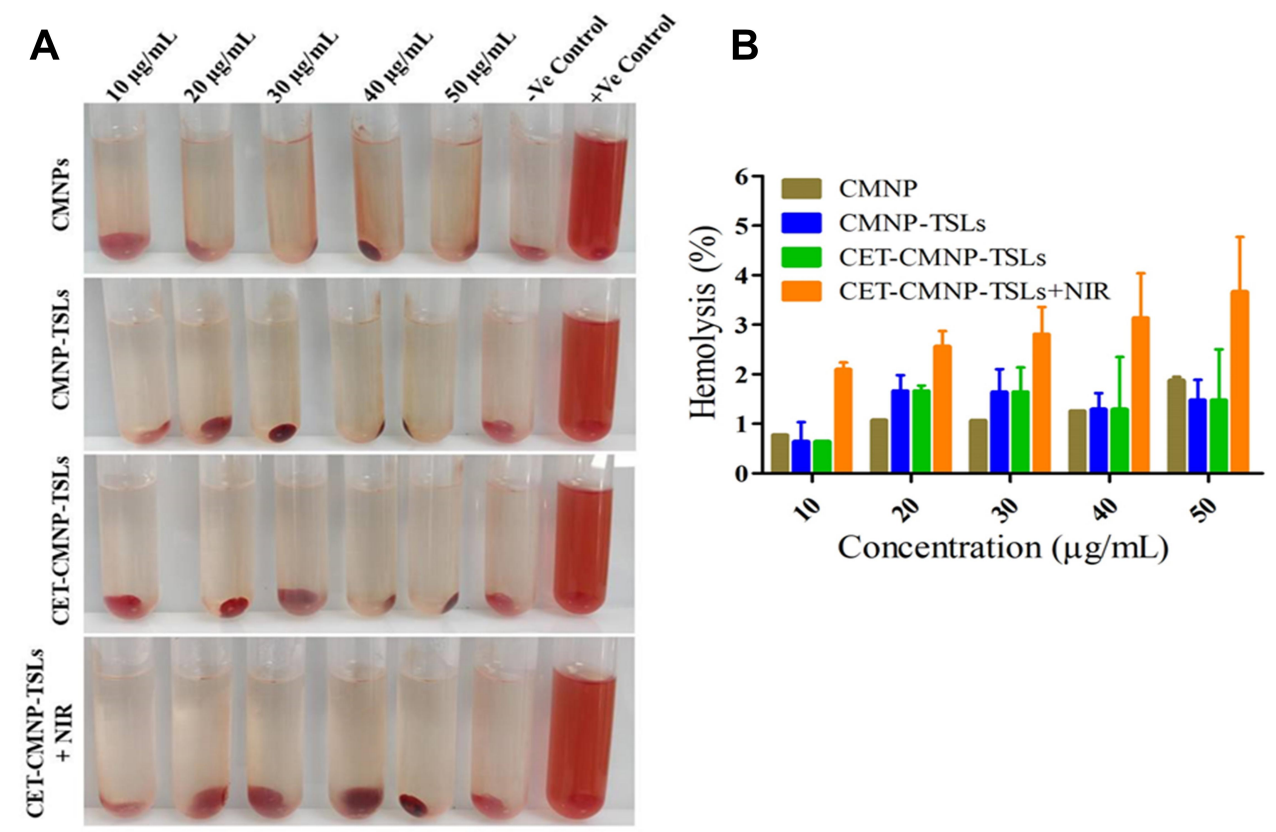

Figure 6 The hemolytic effect of CMNP in all formulations at different concentrations (10, 20, 30, 40, and $50 \mu g / \mathrm{mL})$. (A) Visually observed photographs of rabbit RBCs exposed with different concentrations of CMNPs, normal saline (-Ve control) and deionized water (+Ve control), followed after centrifugation. (B) Quantitative hemolysis rate of CMNPs at concentration ranges from $10-50 \mu \mathrm{g} / \mathrm{mL}$ as measured by a microplate reader (BioTek, USA) at $570 \mathrm{~nm} \lambda_{\text {max }}$.

permeability and retention (EPR) effect in cancer cells. ${ }^{24}$ In our study, the average particle size of the CET-DOX-CMNPTSLs was $117 \pm 3 \mathrm{~nm}$ with a narrow PDI of 0.138 . To load DOX into the TSLs, a $\mathrm{pH}$ gradient method was used as described previously. ${ }^{11}$ DOX and CMNPs loading into the TSLs were enabled by a citric acid coating of MNPs which provides an electrostatic environment. Similar work was reported by others ${ }^{15}$ in which the loading of DOX onto PEGylated-cationic iron oxide was stabilized by citric acid. In our study, we observed a similar organization of DOX inside the TSLs.

pH-dependent DOX release from CMNP-TSLs with and without NIR irradiation was carried out at three different $\mathrm{pH}$ levels, i.e, 7.4, 6.8, and 5.5. The obtained results showed that the release of DOX from NIR irradiated samples in acidic media at $\mathrm{pH} 6.8$ and 5.5 was comparatively higher than at $\mathrm{pH}$ 7.4 and non-irradiated samples. This result is very consistent to work reported by others. ${ }^{25}$ The $\mathrm{pH}$ in the tumor microenvironment is weakly acidic, ie, 6.8, while in endosomes and lysosomes is much more acidic, ie, 5.5. ${ }^{26}$ Therefore, it is logical to assume that the released DOX in tumors is more than in normal tissues at a physiological $\mathrm{pH}$ of 7.4. From this release profile, it can be predicted that during cancer therapy and with the application of NIR irradiation, DOX can be released at higher amounts in tumor cells than in normal tissues and cause less systemic side effects.
Unlike passive delivery, antibody-coated nanoparticles can selectively recognize tumor cells through specific antigen-antibody interactions, leading to effective binding and internalization into cancer cells that could minimize unselective cytotoxicity. ${ }^{27}$ Cancer cells express various types of receptors, with which a specific antibody can bind to facilitate selective antibody-targeted therapeutic effects; these include folate, integrin, and EGFR. ${ }^{28}$ Recently, various researchers have demonstrated the selective internalization of monoclonal antibody-modified nanoparticles in comparison to non-modified nanoparticles. ${ }^{29,30}$

CET is a monoclonal antibody, commonly used to target EGFR receptor for selective binding. ${ }^{3}$ In this study, we exploited the goodness of CET by coating on the outer surface of the DOX-CMNP-TSLs to target EGFR highly expressed breast cancer cells and enter the cells via EGFR-mediated endocytosis. Studies by others and us have demonstrated the selective binding of CET with EGFR expressed on breast cancer cells. ${ }^{7}$ In our cellular uptake study, the uptake of CET-TSLs was greater in comparison with the uptake of TSLs in SKBR-3 cell lines which over-express EGFR than in MCF-7 cell lines which have a lower expression of EGFR; similar results have been reported by others. ${ }^{31-33}$

In the development of novel cancer treatment strategies, combination therapies have often shown better 
efficacy in comparison to monotherapies. ${ }^{34,35}$ Studies have previously shown that increases in temperature induced by NIR irradiation can help drugs to diffuse and sensitize cancer cells to chemotherapeutic drugs, resulting in synergistic anticancer effects. ${ }^{36,37}$ Based on this concept and our current findings, a combination of chemotherapeutic and photo-thermal therapy should be considered as a promising strategy to enhance the anti-cancer impact of chemotherapeutics, whose dosages could be reduced to improve treatment safety profiles.

Iron and gold nanoparticles have been studied for over a decade in various bio-imaging ${ }^{38}$ and thermal therapies, ${ }^{39}$ partly because these compounds produce heat when exposed to external stimuli such as a magnetic field or laser irradiation. Iron-based nanoparticles, for example, have been explored as a possible nanocarrier system for various anti-cancer drugs. ${ }^{38,40}$ To exploit the thermal and magnetic properties of iron oxide, we prepared CMNP and DOX-loaded TSLs that were coated with CET to target EGFR-expressing breast cancer cells.

Cell viability studies are critical to conduct while developing various carriers mediated nanoparticles to deliver chemotherapeutic agents, since the carriers are exogenous substances for cells and possess certain extent of toxicities. In our study, CET-coated CMNP-TSLs were used as carriers to deliver DOX into cancer cells. Figure 4A and B shows the toxicity level of CMNPs as a result of iron in the formulations with and without NIR irradiation in SKBR-3 and MCF-7 breast cancer cells. At higher concentrations of $1000 \mu \mathrm{g} / \mathrm{mL}$, CET-coated formulations in the presence of NIR irradiation showed $60 \%$ and $75 \%$ cell viability after $24 \mathrm{~h}$ of incubation with SKBR-3 and MCF-7 cells, respectively. The cell viability in SKBR-3 cells was comparatively lower than in MCF-7 because of the high expression of EGFR on SKBR-3. Similarly, to explore the possibility of synergistic effects of the DOX and CMNP in CET-coated formulations with and without NIR irradiation, MTT assays were conducted using the same cell lines (Figure 4C and D). As expected, due to the high expression of EGFR on SKBR-3 cells, a lower synergistic effect in comparison to MCF-7 cells (which have lower expression of EGFR) was observed. Our results showed that breast cancer cell viability significantly declined when NIR radiation was added to cells treated with the chemotherapeutic nanocarrier. Free DOX was also able to decrease breast cancer cell viability to a similar but much higher doses were required. These data support the possibility that NIR laser irradiation could be combined with chemotherapeutic nanocarriers to reduce the dose of a chemotherapeutic drug required for treatment efficacy. This possibility is supported by our conclusions in tumor-bearing mice, showing that the tumor surface temperature found during NIR laser irradiated mice treated with CET-CMNP-TSLs or CMNP-TSLs, was substantially greater within $5 \mathrm{~min}$ of irradiation in comparison to the mice treated with normal saline. Lastly, hemolysis assays showed that these nanocarriers are biocompatible and safe.

\section{Conclusion}

Here, we have developed a novel and selective chemotherapeutic nanocarrier system that facilitates drug delivery to EGFR-expressing breast cancer cells enhancing the impact of photo-thermal therapy. These CET-DOX-CMNP-TSLs reduced breast cancer cell viability and increased tumor temperature when combined with NIR laser irradiation. Although iron oxide MNPs are rarely used as a material for photothermal conversion, its in vitro and in vivo photothermal effect was proved to be satisfying in our study and make it a promising nanomaterial for photothermal tumor therapy. Compared to other metal photothermal materials like $\mathrm{Au}$ nanoparticles, iron oxide could be more easily degraded and metabolized in the body. What' more, iron oxide MNPs encapsulating by thermal sensitive liposomes could achieve NIR-triggered drug release behavior which will demonstrate desirable photothermal therapeutic efficiency. Therefore, this delivery system represents a promising therapeutic strategy for improved breast cancer treatment.

\section{Acknowledgments}

This project was supported by the Ministry of Science and Technology of China (NO.2017ZX09101001-005-003), the National Natural Science Foundation of China (NO.81972892 and No. 81673364), the Natural Science Foundation of Jiangsu Province (NO. BK20150702), the Jiangsu Innovation and Entrepreneurship Training Program for Undergraduates (201910316107) and the Applied Technology Research and Development Project of the Inner Mongolia Autonomous Region (2019GG035).

\section{Disclosure}

The authors report no conflicts of interest in this work.

\section{References}

1. Alves CG, de Melo-diogo D, Lima-Sousa R, Costa EC, Correia IJ. Hyaluronic acid functionalized nanoparticles loaded with IR780 and DOX for cancer chemo-photothermal therapy. Eur J Pharm Biopharm. 2019;137:86-94. doi:10.1016/j.ejpb.2019.02.016

2. Wee P, Wang Z. Epidermal growth factor receptor cell proliferation signaling pathways. Cancers (Basel). 2017;9(5):52. 
3. Wang C, Chen S, Yu Q, Hu F, Yuan H. Taking advantage of the disadvantage: employing the high aqueous instability of amorphous calcium carbonate to realize burst drug release within cancer cells. J Mater Chem B. 2017;5(11):2068-2073. doi:10.1039/C6TB02826H

4. Conde J, Bao C, Cui D, Baptista PV, Tian F. Antibody-drug gold nanoantennas with Raman spectroscopic fingerprints for in vivo tumour theranostics. $J$ Control Release. 2014;183:87-93. doi:10.1016/j.jconrel.2014.03.045

5. Karmani L, Labar D, Valembois V, et al. Antibody-functionalized nanoparticles for imaging cancer: influence of conjugation to gold nanoparticles on the biodistribution of $89 \mathrm{Zr}$-labeled cetuximab in mice. Contrast Media Mol Imaging. 2013;8(5):402-408. doi:10.1002/cmmi.1539

6. Kao H-W, Lin -Y-Y, Chen -C-C, et al. Biological characterization of cetuximab-conjugated gold nanoparticles in a tumor animal model. Nanotechnology. 2014;25(29):295102. doi:10.1088/0957-4484/25/29/ 295102

7. Brockhoff G, Heckel B, Schmidt-Bruecken E, et al. Differential impact of cetuximab, pertuzumab and trastuzumab on BT474 and SK-BR-3 breast cancer cell proliferation. Cell Prolif. 2007;40 (4):488-507. doi:10.1111/j.1365-2184.2007.00449.x

8. Roovers RC, Laeremans T, Huang L, et al. Efficient inhibition of EGFR signalling and of tumour growth by antagonistic anti-EGFR nanobodies. Cancer Immunol Immunother. 2007;56(3):303-317. doi:10.1007/s00262-006-0180-4

9. Lupertz R, Watjen W, Kahl R, Chovolou Y. Dose- and time-dependent effects of doxorubicin on cytotoxicity, cell cycle and apoptotic cell death in human colon cancer cells. Toxicology. 2010;271(3):115-121. doi:10.1016/j.tox.2010.03.012

10. Yeh ET, Chang HM. Oncocardiology-past, present, and future: a review. JAMA Cardiol. 2016;1(9):1066-1072. doi:10.1001/ jamacardio.2016.2132

11. Li X, Hirsh DJ, Cabral-Lilly D, et al. Doxorubicin physical state in solution and inside liposomes loaded via a $\mathrm{pH}$ gradient. Biochim Biophys Acta Biomembr. 1998;1415(1):23-40. doi:10.1016/S00052736(98)00175-8

12. Chidambaram M, Manavalan R, Kathiresan K. Nanotherapeutics to overcome conventional cancer chemotherapy limitations. J Pharm Pharm Sci. 2011;14(1):67-77. doi:10.18433/J30C7D

13. Mou X, Ali Z, Li S, He N. Applications of magnetic nanoparticles in targeted drug delivery system. J Nanosci Nanotechnol. 2015;15 (1):54-62. doi:10.1166/jnn.2015.9585

14. Pradhan P, Banerjee R, Bahadur D, Koch C, Mykhaylyk O, Plank C. Targeted magnetic liposomes loaded with doxorubicin. Methods $\mathrm{Mol}$ Biol (Clifton, NJ). 2017;1522:257-272.

15. Gautier J, Munnier E, Paillard A, et al. A pharmaceutical study of doxorubicin-loaded PEGylated nanoparticles for magnetic drug targeting. Int $J$ Pharm. 2012;423(1):16-25. doi:10.1016/j. ijpharm.2011.06.010

16. Quinto CA, Mohindra P, Tong S, Bao G. Multifunctional superparamagnetic iron oxide nanoparticles for combined chemotherapy and hyperthermia cancer treatment. Nanoscale. 2015;7(29):12728-12736. doi:10.1039/C5NR02718G

17. Nedyalkova M, Donkova B, Romanova J, Tzvetkov G, Madurga S, Simeonov V. Iron oxide nanoparticles - In vivo/in vitro biomedical applications and in silico studies. Adv Colloid Interface Sci. 2017;249:192-212. doi:10.1016/j.cis.2017.05.003

18. Estelrich J, Busquets MA. Iron oxide nanoparticles in photothermal therapy. Molecules. 2018;23(7):1567. doi:10.3390/molecules23071567

19. Anilkumar T, Lu Y-J, Chen H-A, Hsu H-L, Jose G, Chen J-P. Dual targeted magnetic photosensitive liposomes for photothermal/photodynamic tumor therapy. J Magn Magn Mater. 2019;473:241-252. doi:10.1016/j.jmmm.2018.10.020

20. Zhu X, Xie Y, Zhang Y, et al. Thermo-sensitive liposomes loaded with doxorubicin and lysine modified single-walled carbon nanotubes as tumor-targeting drug delivery system. J Biomater Appl. 2014;29 (5):769-779. doi:10.1177/0885328214543211
21. Polichetti M, Modestino M, Galluzzi A, et al. Influence of citric acid and oleic acid coating on the dc magnetic properties of $\mathrm{Fe} 3 \mathrm{O} 4$ magnetic nanoparticles. Mater Today. 2020;20:21-24.

22. Lai PS, Lou PJ, Peng CL, et al. Doxorubicin delivery by polyamidoamine dendrimer conjugation and photochemical internalization for cancer therapy. $J$ Control Release. 2007;122(1):39-46. doi:10.1016/j.jconrel.2007.06.012

23. Rosenblum D, Joshi N, Tao W, Karp JM, Peer D. Progress and challenges towards targeted delivery of cancer therapeutics. Nat Commun. 2018;9(1):1410. doi:10.1038/s41467018-03705-y

24. Acharya S, Sahoo SK. PLGA nanoparticles containing various anticancer agents and tumour delivery by EPR effect. Adv Drug Deliv Rev. 2011;63(3):170-183. doi:10.1016/j.addr.2010.10.008

25. Luo Y, Tang F, Wang Y, et al. Safety and efficacy of denosumab in the treatment of pulmonary metastatic giant cell tumor of bone. Cancer Manag Res. 2018;10:1901-1906. doi:10.2147/CMAR. S161871

26. Chaurasiya B, Huang L, Du Y, et al. Size-based anti-tumoral effect of paclitaxel loaded albumin microparticle dry powders for inhalation to treat metastatic lung cancer in a mouse model. Int J Pharm. 2018;542 (1):90-99. doi:10.1016/j.ijpharm.2018.02.042

27. Bi Y, Hao F, Yan G, Teng L, Lee RJ, Xie J. Actively targeted nanoparticles for drug delivery to tumor. Curr Drug Metab. 2016;17(8):763-782. doi:10.2174/1389200217666160619191853

28. Danhier F, Feron O, Preat V. To exploit the tumor microenvironment: passive and active tumor targeting of nanocarriers for anti-cancer drug delivery. J Control Release. 2010;148(2):135-146. doi:10.10 16/j.jconrel.2010.08.027

29. Jiang S, Wang X, Zhang Z, et al. CD20 monoclonal antibody targeted nanoscale drug delivery system for doxorubicin chemotherapy: an in vitro study of cell lysis of CD20-positive Raji cells. Int J Nanomedicine. 2016;11:5505-5518. doi:10.2147/IJN. S115428

30. Colzani B, Pandolfi L, Hoti A, et al. Investigation of antitumor activities of trastuzumab delivered by PLGA nanoparticles. Int $J$ Nanomedicine. 2018;13:957-973. doi:10.21 47/IJN.S152742

31. Zhang X, Li Y, Wei M, Liu C, Yu T, Yang J. Cetuximab-modified silica nanoparticle loaded with ICG for tumor-targeted combinational therapy of breast cancer. Drug Deliv. 2019;26(1):129-136. doi:10.10 80/10717544.2018.1564403

32. Tol J, Dijkstra JR, Klomp M, et al. Markers for EGFR pathway activation as predictor of outcome in metastatic colorectal cancer patients treated with or without cetuximab. Eur J Cancer. 2010;46 (11):1997-2009. doi:10.1016/j.ejca.2010.03.036

33. Sun X, Luo Y, Huang L, Yu B-Y, Tian J. A peptide-decorated and curcumin-loaded mesoporous silica nanomedicine for effectively overcoming multidrug resistance in cancer cells. RSC Adv. 2017;7 (27):16401-16409. doi:10.1039/C7RA01128H

34. Yu X, Zhu W, Di Y, et al. Triple-functional albumin-based nanoparticles for combined chemotherapy and photodynamic therapy of pancreatic cancer with lymphatic metastases. Int $J$ Nanomedicine. 2017;12:6771-6785. doi:10.2147/IJN.S131295

35. Xie J, Fan Z, Li Y, et al. Design of $\mathrm{pH}$-sensitive methotrexate prodrug-targeted curcumin nanoparticles for efficient dual-drug delivery and combination cancer therapy. Int $J$ Nanomedicine. 2018;13:1381-1398. doi:10.2147/IJN.S152312

36. Wang Z, Chen Z, Liu Z, et al. A multi-stimuli responsive gold nanocage-hyaluronic platform for targeted photothermal and chemotherapy. Biomaterials. 2014;35(36):9678-9688. doi:10.1016/j. biomaterials.2014.08.013

37. Li J, Lyv Z, Li Y, et al. A theranostic prodrug delivery system based on $\mathrm{Pt}(\mathrm{IV})$ conjugated nano-graphene oxide with synergistic effect to enhance the therapeutic efficacy of $\mathrm{Pt}$ drug. Biomaterials. 2015;51:12-21. doi:10.1016/j.biomaterials.2015.01.074 
38. Pandey S, Thakur M, Mewada A, Anjarlekar D, Mishra N, Sharon M. Carbon dots functionalized gold nanorod mediated delivery of doxorubicin: tri-functional nano-worms for drug delivery, photothermal therapy and bioimaging. J Mater Chem B. 2013;1(38):4972-4982. doi:10.1039/c3tb20761g

39. Khafaji M, Vossoughi M, Hormozi-Nezhad MR, Dinarvand R, Börrnert F, Irajizad A. A new bifunctional hybrid nanostructure as an active platform for photothermal therapy and MR imaging. Sci Rep. 2016;6(1):27847. doi:10.1038/srep27847
40. Oh Y, Je JY, Moorthy MS, Seo H, Cho WH. pH and NIR-lightresponsive magnetic iron oxide nanoparticles for mitochondria-mediated apoptotic cell death induced by chemo-photothermal therapy. Int $J$ Pharm. 2017;531(1):1-13. doi:10.1016/j.ijpharm.2017.07.014

\section{Publish your work in this journal}

The International Journal of Nanomedicine is an international, peerreviewed journal focusing on the application of nanotechnology in diagnostics, therapeutics, and drug delivery systems throughout the biomedical field. This journal is indexed on PubMed Central, MedLine, CAS, SciSearch ${ }^{\mathbb{B}}$, Current Contents ${ }^{\mathbb{B}} /$ Clinical Medicine, $^{2}$
Journal Citation Reports/Science Edition, EMBase, Scopus and the Elsevier Bibliographic databases. The manuscript management system is completely online and includes a very quick and fair peer-review system, which is all easy to use. Visit http://www.dovepress.com/ testimonials.php to read real quotes from published authors.

Submit your manuscript here: https://www.dovepress.com/international-journal-of-nanomedicine-journal 